Article

\title{
Poly (3,4-Ethylenedioxythiophene) (PEDOT) Nanofibers Decorated Graphene Oxide (GO) as High-Capacity, Long Cycle Anodes for Sodium Ion Batteries
}

\author{
Zejun Pu ${ }^{1}$, Penglun Zheng ${ }^{2, *}$ and Yu Zhang ${ }^{3, *}$ \\ 1 College of Materials Science and Engineering, Sichuan University of Science \& Engineering, Zigong 643000, \\ China; puzejunuestc@163.com \\ 2 High Temperature Resistant Polymer and Composites Key Laboratory of Sichuan Province, \\ University of Electronic Science and Technology of China, Chengdu 610054, China \\ 3 School of Materials Science and Engineering, Nanyang Technological University, 50 Nanyang Avenue, \\ Singapore 639798, Singapore \\ * $\quad$ Correspondence: 18482179228@163.com (P.Z.); yzhang071@e.ntu.edu.sg (Y.Z.)
}

Received: 21 September 2018; Accepted: 16 October 2018; Published: 19 October 2018

\begin{abstract}
Conductive Poly (3,4-ethylenedioxythiophene) (PEDOT) nanofibers are uniformly deposited on ultrathin graphene oxide (GO) nanosheets via a simple and effective in situ polymerization process under ambient conditions. The as-prepared samples are characterized by field-emission scanning electron microscopy (FE-SEM), transmission electron microscopy (TEM), Raman spectra, Fourier transforms infrared spectra (FTIR), and electrochemical measurements. The results indicate that the as-obtained PEDOT-GO hybrid (GDOT) achieves excellent sodium storage properties. When explored as a new inorganic/polymeric electrode for sodium ion batteries (SIBs), the GDOT exhibits a high reversible capacity (338 mAh g ${ }^{-1}$ ), good cycling stability ( $234 \mathrm{mAh} \mathrm{g}^{-1}$ after 400 cycles), and excellent rate capabilities (e.g., $62 \mathrm{mAh} \mathrm{g}^{-1}$ at $30 \mathrm{~A} \mathrm{~g}^{-1}$ ) due to their ultrathin structure as well as conductive network. This easily scale-up-able and effective strategy shows great potential for large-scale energy applications.
\end{abstract}

Keywords: graphene oxide; in-situ polymerization; conductive polymer; hybrid; sodium ion battery

\section{Introduction}

Lithium ion batteries (LIBs) have been the leading energy storage technology for portable devices and electrical vehicles (EVs) during the past two decades. However, the challenges for its large-scale application are the scarcity of lithium source as well as its high cost [1-3]. Sodium ion batteries (SIBs) have attracted emerging scientific attention as an alternative to LIBs as next-generation energy storage technology due to the abundance ( 2.5\% in the Earth's cost), low cost, as well as similar chemistry properties of sodium to lithium [4]. However, SIBs are confronted with the challenges in terms of low energy density, low power density, and inferior cycle life. To address these issues, intensive work has been performed on developing electrode materials, especially cathode materials [5]. However, research on the anode materials for SIBs is still in its infancy due to the unsuccessful adaptation of LIBs electrodes to SIBs [6]. For example, graphite as the most common anode materials for commercial LIBs has been demonstrated electrochemically inactive with a very low capacity [7,8]. In addition, other well-developed anodes for LIBs, such as alloying-type materials (Sn [9], Sb [10], P [11], etc.) and transition metal oxides/sulphides ( $\mathrm{CoO}$ [12], $\mathrm{FeS}_{2}$ [13], etc.) are hindered by the large volume change and sluggish sodiation kinetics, leading to inferior rate capability as well as poor cycling stability. Therefore, developing appropriate anode materials for SIBs with high rate capability and excellent cycling life still requires further effort before putting into practical application. 
Carbonaceous materials (e.g., carbon nanotube [14], expanded graphite [15], and reduced graphene oxide (rGO) [16], etc.) are considered as potential anodes for SIBs owing to its naturally abundant distribution and environmental benignity. Moreover, they are free from huge volume change compared with those conversion and alloy type anodes during the Na ion (de-) insertion [17]. However, challenges remain regarding their unsatisfactory electrochemical properties as well as large-scale applications. For example, hard carbon exhibits poor rate capability due to its lower electronic conductivity and limited nanopore-filling sodium ion process compared to other carbon materials like rGO [18]. Expanding graphite has been reported as an effective strategy towards the inactive pristine graphite for SIBs, but its capacity falls from $284 \mathrm{mAh} \mathrm{g}^{-1}$ at $20 \mathrm{~mA} \mathrm{~g}^{-1}$ to $91 \mathrm{mAh} \mathrm{g}^{-1}$ at $200 \mathrm{~mA} \mathrm{~g}^{-1}$. In addition to hard carbon and graphite, $\mathrm{rGO}$ with a novel 2D structure has attracted much attention as a promising Na-ion storage material due to its outstanding electronic conductivity, high surface-to-volume ratio, and good flexibility [16]. Nonetheless, rGO sheets tend to restack, which leads to difficult slurry processing as well as poor capacity retention during cycling [19]. In addition, rGO are generally prepared by thermal or chemical reduction process of GO, which needs multiple operation process, high-temperature conditions, or specific atmosphere [20]. Alternatively, graphene oxide (GO) can be prepared in a large scale by the well-developed Hummers' method [21]. It is known that low cost and scalability of electrode synthesis are crucial for practical applications. Furthermore, GO readily dissolves in N-Methyl-2-pyrrolidone (NMP) or aqueous solvents due to its hydrophilic property, which are favorable features for electrode processing [22]. However, GO is electrically insulating, and few studies have been reported on the development of GO as the anode for SIBs. Therefore, we are inspired to develop approaches to prepare efficient GO-based anode for SIBs.

Nanoscale surface engineering of electrode materials plays a key role in the interfacial reactions between electrodes and electrolyte. Herein, we report effective surface engineering of GO by homogeneously bottom-up growing conductive polymer-PEDOT (Poly (3,4-ethylenedioxythiophene)) nanofibers on GO nanosheets via a facile in situ polymerization process and study its sodium storage properties. The resulting PEDOT-GO hybrid (GDOT) architecture possesses the following merits: (1) ultrathin configuration endowing short ion diffusion path; (2) much improved electrical conductivity facilitating fast charge transfer; (3) high specific surface areas providing sufficient active sites; and most importantly (4) easily scale-up-able methodology under ambient conditions. Benefiting from these unique characteristics, the as-synthesized GDOT electrodes present a high reversible capacity of $338 \mathrm{mAh} \mathrm{g}^{-1}$ at $100 \mathrm{~mA} \mathrm{~g}^{-1}$, preferable rate (e.g., $136 \mathrm{mAh} \mathrm{g}^{-1}$ at $10 \mathrm{~A} \mathrm{~g}^{-1}$ ) and cycling performance ( $234 \mathrm{mAh} \mathrm{g}^{-1}$ after 400 cycles at $100 \mathrm{~mA} \mathrm{~g}^{-1}$ ) when working as the anode for SIBs.

\section{Experimental Section}

Synthesis of GO: high-quality graphite oxide was prepared from natural graphite powder (325 mesh) according to the modified Hummers' method as reported by Du [23]. Firstly, $6 \mathrm{~g}$ graphite powder was dispersed in $48 \mathrm{~mL} 98 \% \mathrm{H}_{2} \mathrm{SO}_{4}$ followed by the addition of $10 \mathrm{~g} \mathrm{~K}_{2} \mathrm{~S}_{2} \mathrm{O}_{8}$, and $10 \mathrm{~g}$ of $\mathrm{P}_{2} \mathrm{O}_{5}$ to form a homogeneous solution with a physical dispersion technology, which utilized a ball milling machine by high-speed circulation $(15,000 \mathrm{rpm}, 10 \mathrm{~min})$. Then, the mixture solution was transferred to a $100 \mathrm{~mL}$ three-necked round bottom flask and maintained at $80^{\circ} \mathrm{C}$ for $4.5 \mathrm{~h}$. After cooling naturally to room temperature, the preoxidized products were obtained by centrifuging and rinsed for 3-4 times to remove residuum. In addition, the preoxidized products were dried under vacuum at $60{ }^{\circ} \mathrm{C}$ for $12 \mathrm{~h}$. After that, the as-prepared preoxidized products were homogeneously dispersed in $240 \mathrm{~mL} 98 \%$ $\mathrm{H}_{2} \mathrm{SO}_{4}$ solution by ultrasonic dispersion technology, $30 \mathrm{~g}$ of $\mathrm{KMnO}_{4}$ was then slowly added into the above solution with a low temperature $\left(<20^{\circ} \mathrm{C}\right)$ to avoid overheating and explosion. Subsequently, the temperature of solution was increased to $35^{\circ} \mathrm{C}$ and kept for another $2 \mathrm{~h}$. After $2 \mathrm{~h}, 1400 \mathrm{~mL} \mathrm{H}_{2} \mathrm{O}$ was slowly added to dilute the above solution, and $800 \mathrm{~mL} 30 \% \mathrm{H}_{2} \mathrm{O}_{2}$ was trickled into the mixture solution to completely react with the superfluous $\mathrm{KMnO}_{4}$. After the reaction, the bright yellow mixture solution was filtered using a 0.2- $\mu \mathrm{m}$ PTFE filter membrane and washed by distilled (DI) water for 
3 times. Ultimately, the neutral GO aqueous solution was freeze-dried to remove the remaining water inside and the high-quality GO powder was obtained.

Fabrication of GDOT: the as-prepared high-quality GO $(20 \mathrm{mg})$ was further homogeneously dispersed in a mixed solution of DI water $(10 \mathrm{~mL})$ and ethanol $(30 \mathrm{~mL})$ via a short sonication, following by adding $40 \mu \mathrm{L}$ of EDOT with the help of magnetic stirring for $15 \mathrm{~min}$, and simultaneously $270 \mathrm{mg}$ $\mathrm{FeCl}_{3}$ was dissolved in $10 \mathrm{~mL}$ ethanol. The $\mathrm{FeCl}_{3} /$ ethanol solution was added slowly into the above solution, and then the mixed solution was first maintained violently stirring ( $2000 \mathrm{rpm}$ ) for $5 \mathrm{~min}$ and then maintained slow stirring ( $400 \mathrm{rpm}$ ) for another $20 \mathrm{~min}$ and $40 \mathrm{~min}$, respectively. Ultimately, the PEDOT-GO hybrids, namely GDOT, were obtained after centrifuging and washing with DI water and ethanol, respectively.

Measurement and Characterization: Field-emission scanning electron microscopy (FE-SEM, JEOL JSM-7600F, Tokyo, Japan) and Transmission electron microscopy (TEM, JEOL-2100F, Tokyo, Japan) were applied to observe the micro-morphology of the as-prepared GO, GDOT, and pure PEDOT fibers, respectively. Raman spectra of GO was recorded from 600 to $2500 \mathrm{~cm}^{-1}$ on a micro-Raman spectrometer (Witec CRM200, WITec GmbH, Germany). Fourier transform infrared (FTIR, NICOLET 6700, Waltham, Massachusetts, America) was utilized to investigate the structure of pure GO and GDOT between $550 \mathrm{~cm}^{-1}$ and $3200 \mathrm{~cm}^{-1}$. The preparation of electrode slurries and assembly of coin cells (2032) were carried out as described in the previous literature [6]. For a direct comparison, the electrochemical activities of the Single-Walled Carbon Nanotubes (SWCNT) were investigated and are presented in Figure S1 (Supporting Information). The charge and discharge tests were carried out by a LAND battery tester with a voltage window of 0.01-3.0 V. Cyclic voltammetry (CV) curves and electrochemical impedance spectroscopy (EIS) measurements for GDOT and GO electrodes were carried out in the AC frequency (from $1 \mathrm{MHz}$ to $0.01 \mathrm{~Hz}$ ) using a Bio-Logic SP-150 model potentiostat.

\section{Results and Discussion}

GO nanosheets were obtained by the well-developed Hummers' method. The preparation of GDOT nanosheets involves the following steps as shown in Figure 1. In brief, GO was dispersed into the mixture of DI water and ethanol via sonication. Subsequently, 3,4-ethylenedioxythiophene (EDOT) molecules were added and absorbed onto the surface of GO by hydrogen bonding between the functional groups of GO surface and the oxygen atoms in EDOT monomers. Ultimately, the PEDOT fibers were uniformly decorated onto GO via in situ polymerization with controlled reaction time under ambient conditions.

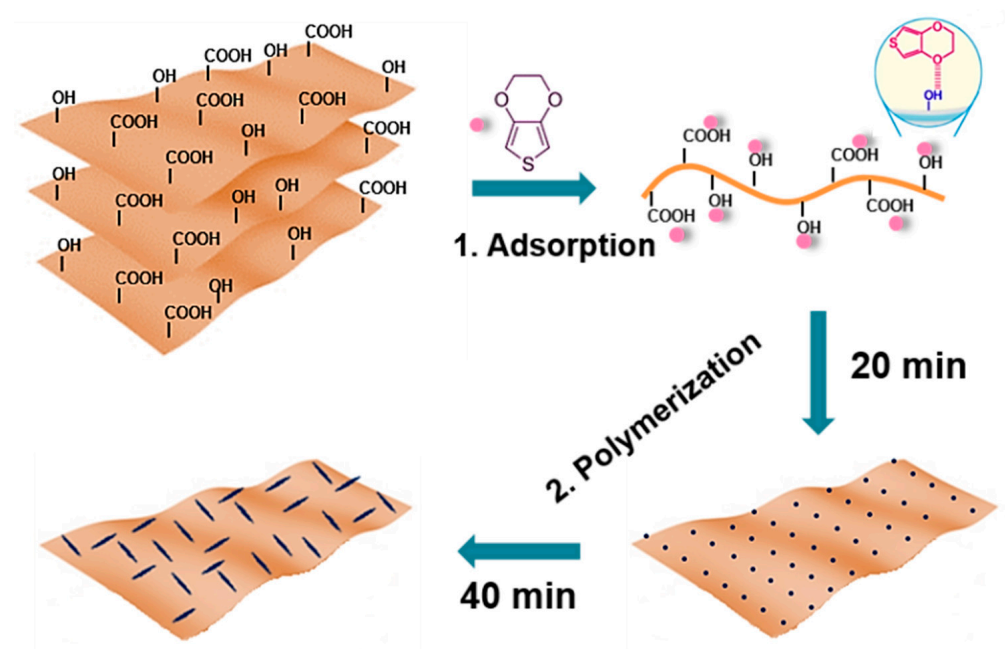

Figure 1. Schematic diagram of the fabrication of process for GDOT architectures: (1) Adsorption of EDOT on the surface of GO by hydrogen bonding. (2) In situ polymerization of PEDOT nanofibers on GO with controlled reaction time under ambient conditions. PEDOT, Poly (3,4-ethylenedioxythiophene); GO, graphene oxide; GDOT, PEDOT-GO hybrid. 
The as-obtained GO was characterized by Raman spectra, FE-SEM, and TEM, respectively. Figure 2 displays the Raman spectra of pure GO, two prominent broad peaks at around $1365 \mathrm{~cm}^{-1}$ and $1597 \mathrm{~cm}^{-1}$ can be obviously observed, which can be ascribed to the disorder induced D band and the first-order scattering of $E_{2 g}$ allowed $G$ band [24]. Figure 3a,b shows the FE-SEM and TEM images of GO, respectively. As shown in Figure 3a, the GO on silicon wafer shows smooth and planar surface with several micrometer in lateral size. The TEM image (Figure 3b) shows a typical transparent nanosheet, proving the ultrathin nature of GO. Then, the GDOT hybrid nanosheets were synthesized by in situ polymerization of EDOT monomers absorbing on $\mathrm{GO}$ in the presence of $\mathrm{FeCl}_{3}$. The structural evolution was examined by controlling the reaction time. It is observed that uniform PEDOT nanodots are firstly grown on the GO surface within $20 \mathrm{~min}$ (Figure 3c). The size of PEDOT nanodots could be determined as ca. $2 \mathrm{~nm}$ by the high-magnification TEM image (Figure 3d). PEDOT fibers (length: $\approx 100 \mathrm{~nm}$; diameter: $\approx 10 \mathrm{~nm}$ ) are successfully formed within $40 \mathrm{~min}$, as shown in Figure 3e,f.

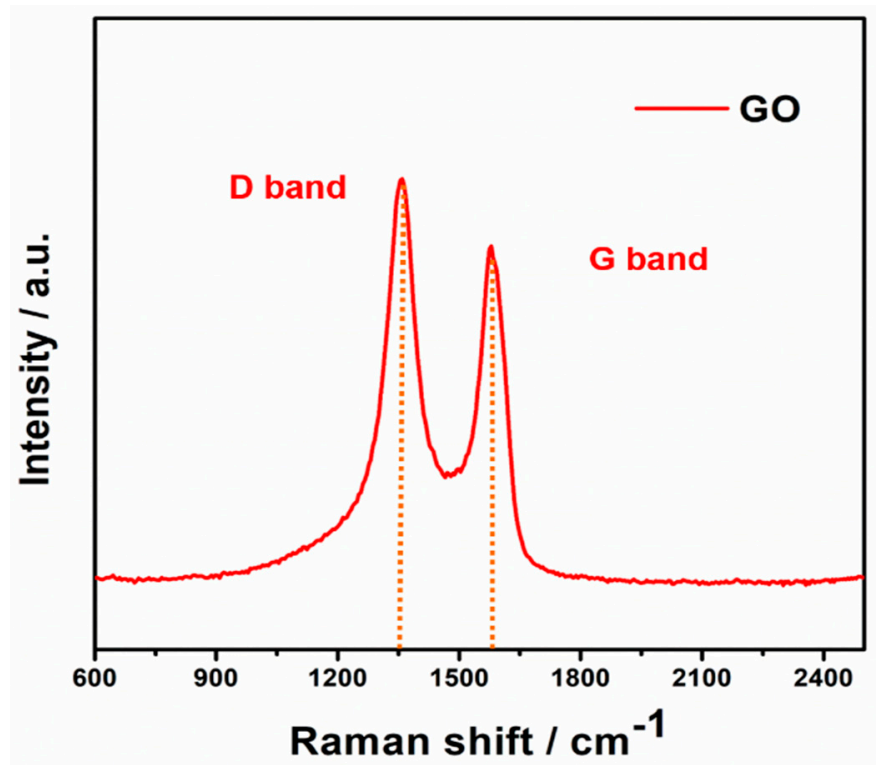

Figure 2. Raman spectra of GO with two prominent peaks at $1365 \mathrm{~cm}^{-1}$ and $1597 \mathrm{~cm}^{-1}$, respectively.
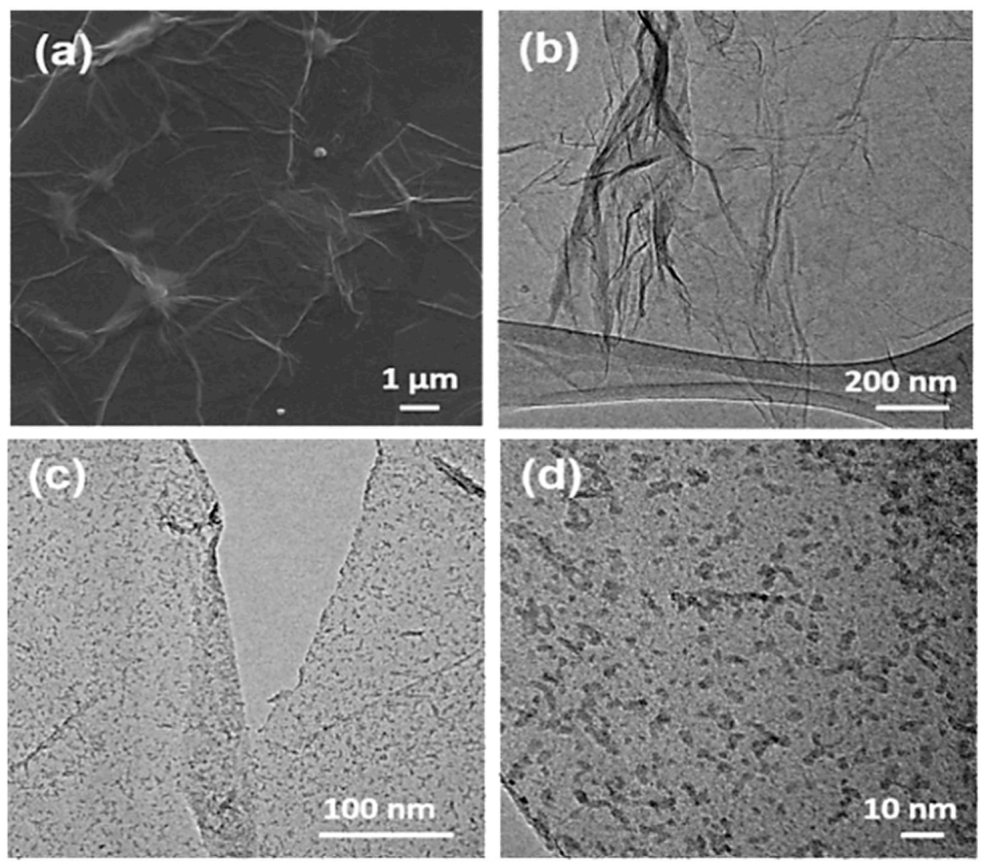

Figure 3. Cont. 

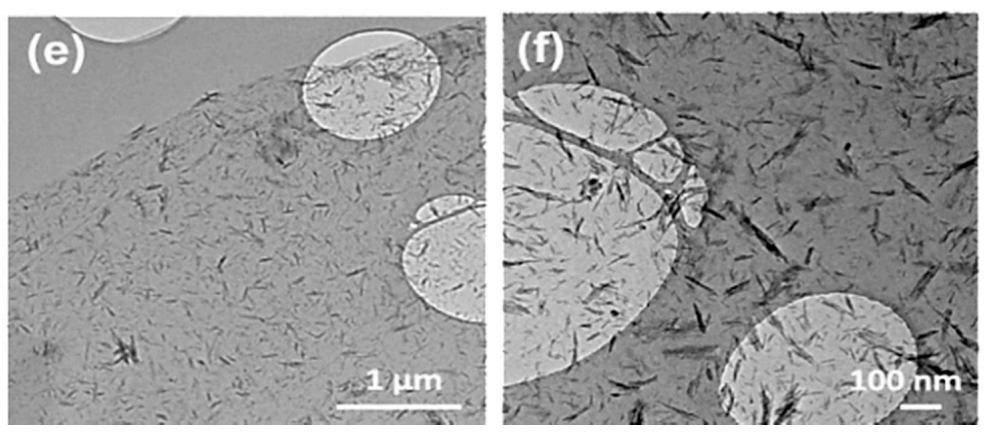

Figure 3. Characterizations of GO and GDOT: FE-SEM (a) and TEM (b) images of GO; TEM images of GDOT obtained within reaction time of $20 \mathrm{~min}(\mathbf{c}, \mathbf{d})$ and $40 \mathrm{~min}(\mathbf{e}, \mathbf{f})$.

Furthermore, the PEDOT fibers were prepared without adding GO, and their TEM image is presented in Figure 4. The results suggest from another point of view that the PEDOT fibers were uniformly deposited on ultrathin graphene oxide (GO) nanosheets by a facile in situ polymerization process.

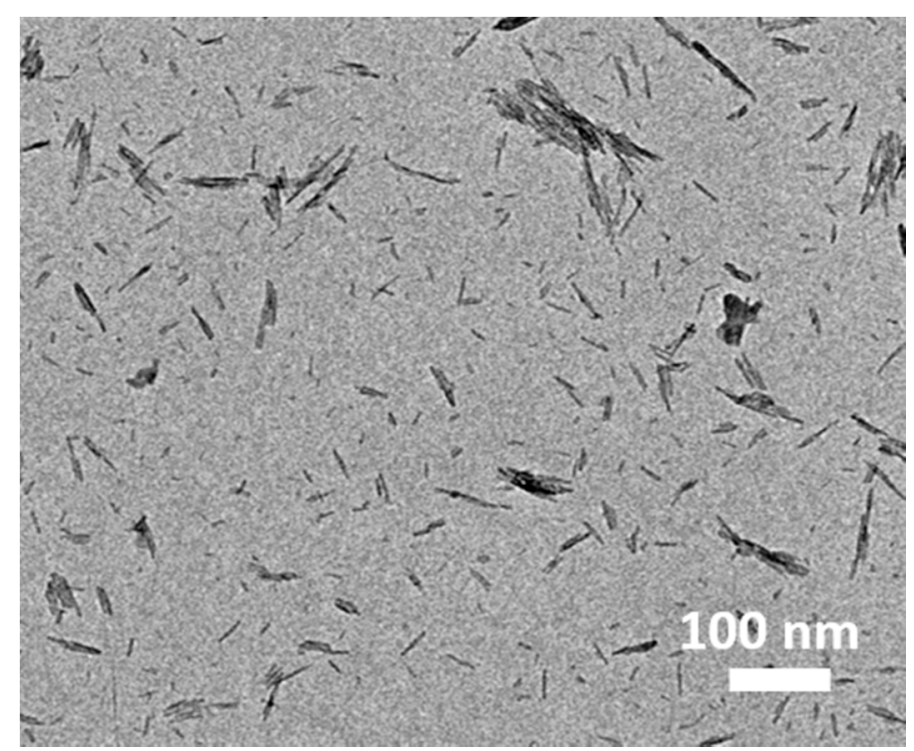

Figure 4. TEM image of the pure PEDOT fibers.

To further confirm the presence of PEDOT, FTIR measurement was performed on the GO and GDOT hybrid. In Figure 5a, the same peaks from both samples located at 1107, 1391, 1627, 1738, 2365 , 2849, and $2919 \mathrm{~cm}^{-1}$ belonging to the $\mathrm{C}-\mathrm{O}, \mathrm{C}-\mathrm{O}, \mathrm{C}=\mathrm{C}, \mathrm{C}=\mathrm{O}, \mathrm{CO}_{2}$ and $\mathrm{C}-\mathrm{H}$ bond vibrations, respectively, which could originate from graphene oxide or PEDOT [25]. It's worth noting that a bond at $982.0 \mathrm{~cm}^{-1}$ for the GDOT sample can be observed, which belongs to the C-S bond vibration of PEDOT, while it is missing in GO. This indicates the successful growth of PEDOT on GO nanosheet. Furthermore, the high-angle annular dark-field scanning TEM (HAADF-STEM, Figure 5b) image and their corresponding element mapping (Figure $5 c, d$ ) show the uniform distribution of $C$ and $S$ element in a typical nanosheet, further confirming the presence of PEDOT in GDOT hybrid. 

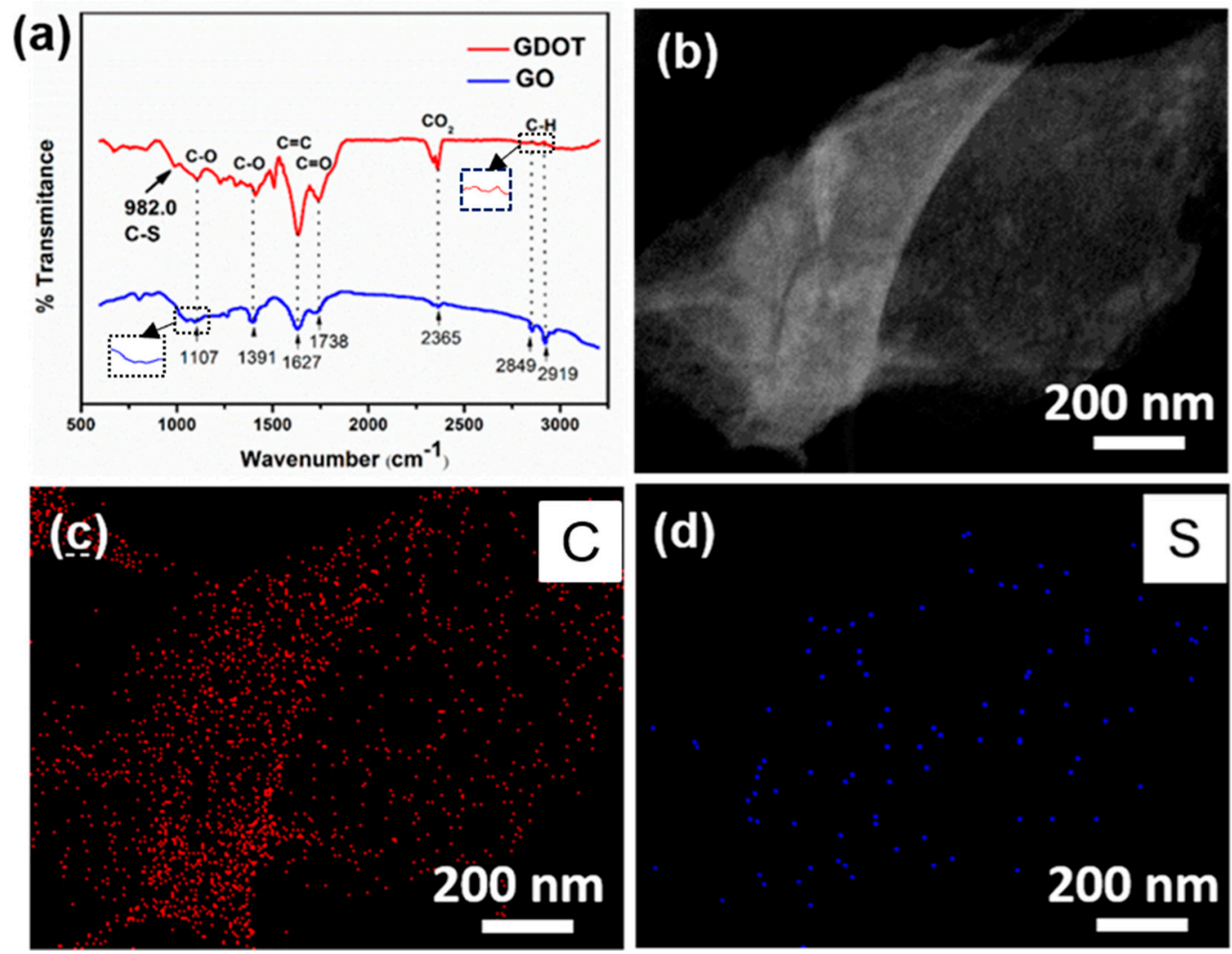

Figure 5. (a) FTIR measurements of GDOT and GO; (b) HAADF-STEM image of GDOT; and (c,d) the corresponding element mapping.

The sodium storage properties of the GDOT hybrid were investigated based on the standard half-cell configuration with sodium foil as the counter/reference electrode. Figure 6a shows the initial three cycles of the discharge-charge curves for the GDOT electrode at a current density of $100 \mathrm{~mA} \mathrm{~g}^{-1}$ within the potential window of 0.05 to $3.0 \mathrm{~V}$ versus $\mathrm{Na} / \mathrm{Na}^{+}$. During the initial discharging process, a plateau at approximately $1.25 \mathrm{~V}$ was observed and disappeared in the following cycles, which was related to the formation of solid electrolyte interphase (SEI) on GDOT surface and the reaction between the functional groups (e.g., $-\mathrm{OH},-\mathrm{COOH}$, etc.) on $\mathrm{GO}$ with $\mathrm{Na}^{+}$. For the charging process, no apparent plateau was recorded, indicating that $\mathrm{Na}^{+}$ion extraction from the electrode has no specific voltage range. Slightly higher working potentials than hard carbon and no obvious voltage hysteresis are observed in the discharge and charge profiles, suggesting the possible alloying reaction during sodiation and desodiation process [26]. Initial discharge and charge capacities of $1278 \mathrm{mAh} \mathrm{g}^{-1}$ and $338 \mathrm{mAh} \mathrm{g}^{-1}$ were achieved, respectively. The resulting relatively low coulombic efficiency (CE) could be due to the SEI formation and other irreversible reactions between the active groups on $\mathrm{GO}$ with $\mathrm{Na}^{+}$, which is similar to those carbon-based materials reported previously [8]. During the following two cycles, the discharge-charge curves are almost overlapping, implying its good reversibility. The rate capability is a crucial aspect for high-performance SIBs. The rate performance of the GDOT electrode was evaluated at different current densities ranging from 0.1 to $30 \mathrm{~A} \mathrm{~g}^{-1}$. In Figure $6 \mathrm{~b}$, the GDOT electrode delivered high reversible specific capacities of 288, 261, 231, 208, 179, and $139 \mathrm{mAh} \mathrm{g}^{-1}$ at $0.2,0.5,1,2,5$, and $10 \mathrm{~A} \mathrm{~g}^{-1}$, respectively. It should be noted that remarkable specific capacities of 95.0 and $62.3 \mathrm{~mA} \mathrm{~h} \mathrm{~g}^{-1}$ were sustained even at high current densities of 20 and $30 \mathrm{~A} \mathrm{~g}^{-1}$, respectively. In addition, a specific capacity of $192 \mathrm{mAh} \mathrm{g}^{-1}$ can still be returned when the current density is set back to $0.1 \mathrm{~A} \mathrm{~g}^{-1}$. As a comparison, bare GO electrode delivered reversible capacities of $104,73,56$, $38 \mathrm{mAh} \mathrm{g}^{-1}, 25 \mathrm{mAh} \mathrm{g}^{-1}$ at $0.2,0.5,1,2,5 \mathrm{~A} \mathrm{~g}^{-1}$, respectively and negligible reversible capacities (e.g., $10 \mathrm{mAh} \mathrm{g}^{-1}$ at $30 \mathrm{~A} \mathrm{~g}^{-1}$ ) at high current densities, which are much lower than those of the GDOT 
electrode. The cycling stability of bare GO, PEDOT, and GDOT hybrid for SIBs was also evaluated at $100 \mathrm{~mA} \mathrm{~g}^{-1}$ within the potential window of 0.005-3.0 V. In Figure $6 \mathrm{c}$, a high specific capacity of $234 \mathrm{mAh} \mathrm{g}^{-1}$ can be maintained for GDOT after 400 cycles at $100 \mathrm{~mA} \mathrm{~g}^{-1}$, which is almost 2.4 times that of the GO electrode $\left(97 \mathrm{mAh} \mathrm{g}^{-1}\right)$. The pure PEDOT electrode shows fast capacity fading from 385 to $62 \mathrm{mAh} \mathrm{g}^{-1}$ during 200 cycles (Figure 7), which might originate from its large volume change. Based on the discussion, one can see that significantly enhanced rate capability and cycling performance are obtained for GDOT, which is due to the following several reasons: First, the hydrophilic GO can serve as an efficient reservoir for the electrolyte, and thus facilitates the migration of $\mathrm{Na}^{+}$. Furthermore, the uniform distribution of conductive fibers on GO surface significantly enhances the charge transfer by providing electron highway. In addition, the ultrathin GO as matrix can boost the accommodation ability towards large volume change.
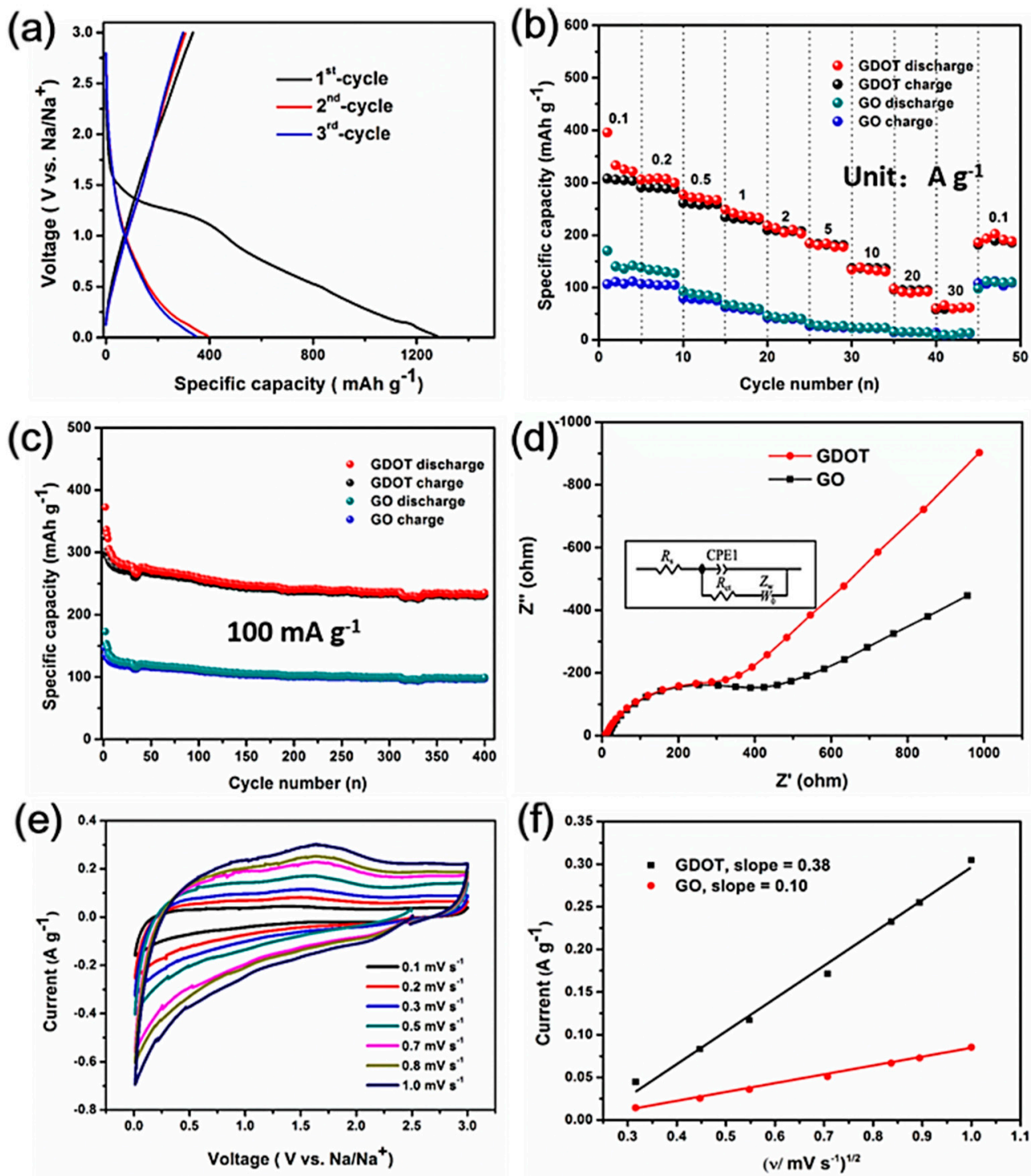

Figure 6. Electrochemical activity of GDOT and GO electrodes for SIBs: (a) The first three cycles discharge-charge curves of the GDOT electrode; (b) rate capability at different current densities from 0.1 to $30 \mathrm{~A} \mathrm{~g}^{-1}$; (c) cycling performance at $0.1 \mathrm{~A} \mathrm{~g}^{-1}$; (d) the electrochemical impedance spectra measurements (inset: fitted equivalent circuit); (e) CV curves of GDOT electrode at different scan rates from 0.1 to $1.0 \mathrm{mV} \mathrm{s}^{-1}$; and (f) linear relationship of the cathodic peak current $\left(\mathrm{i}_{\mathrm{p}}\right)$ and the square root of scan rate $\left(v^{1 / 2}\right)$. 


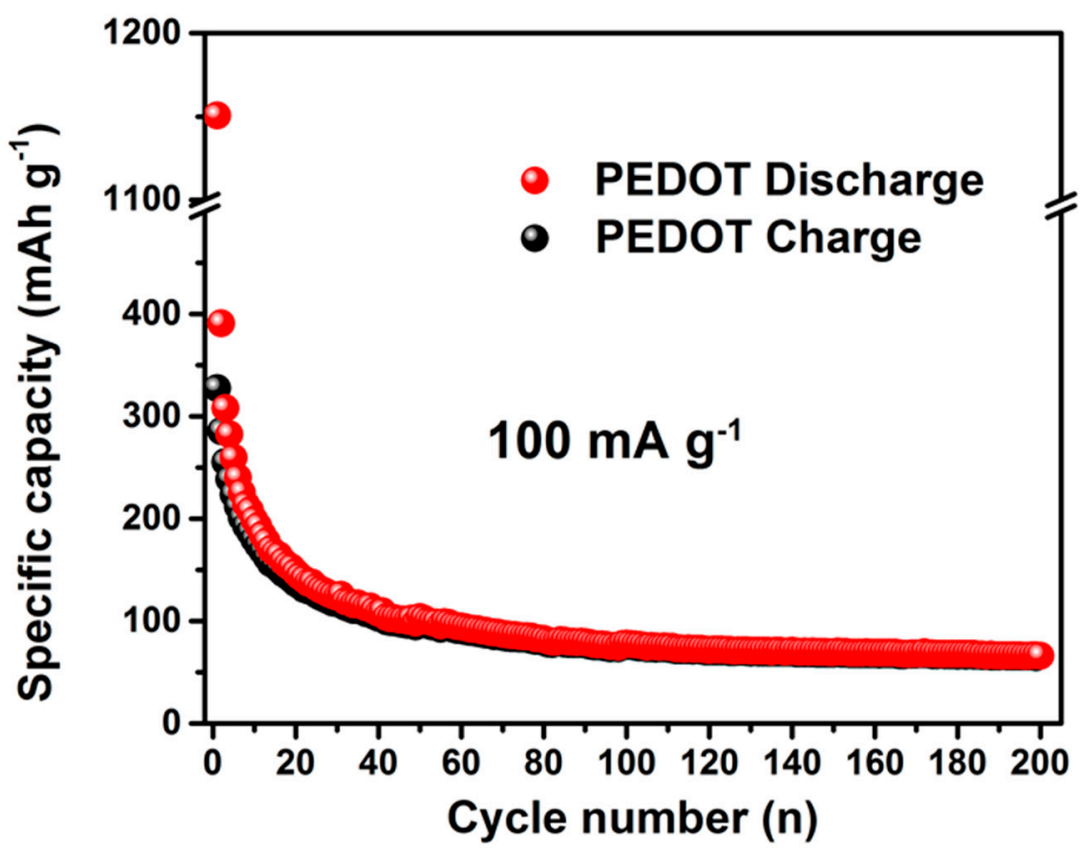

Figure 7. Cycling performance of the pure PEDOT electrode for SIBs at a current density of $100 \mathrm{~mA} \mathrm{~g}^{-1}$.

To have a good understanding of the improved sodium storage properties, the EIS measurements were carried out after the third fully charged state. In Figure $6 \mathrm{~d}$, the semicircle in the high-middle frequency range corresponds to the charge transfer resistance $\left(R_{c t}\right)$ between the electrolyte and the electrodes. The low frequency line represents the Warburg resistance (Wo) related to the Li ion diffusion in electrode materials. From the fitted equivalent circuit in the inset of Figure $6 \mathrm{~d}$, the $\mathrm{R}_{\mathrm{ct}}$ of the GDOT electrode $(232 \Omega)$ is much lower than that of the pure GO electrode $(395 \Omega)$, implying that the GDOT electrode possesses lower resistance. In addition, the CV measurements were also carried out on half cells at different scan rates from 0.1 to $1 \mathrm{mV} \mathrm{s}^{-1}$. In Figure 6e, the intensity of CV profiles for the GDOT electrode increases with the scan rate and shows no obvious distortion, indicating its quick CV response and fast reaction kinetics. According to the classical Randles-Sevchik equation (Equation (1)):

$$
\mathrm{i}_{\mathrm{p}}=\left(2.69 \times 10^{5}\right) n^{3 / 2} S D^{1 / 2} C v^{1 / 2}
$$

where $i_{p}, n, S, D, C$, and $v$ represents the peak current (A), charge-transfer number, electrode area, diffusion coefficient of $\mathrm{Na}^{+}\left(\mathrm{cm}^{2} \mathrm{~s}^{-1}\right)$, concentration of sodium ions, and potential scan rate $\left(\mathrm{V} \mathrm{s}^{-1}\right)$, respectively. In addition, the above formula can be simplified to as:

$$
\mathrm{i}_{\mathrm{p}}=A D^{1 / 2} C v^{1 / 2}
$$

where $\mathrm{A}$ is considered a constant for the three cells and $A D^{1 / 2}$ can be supposed to be the apparent diffusion constant (ADC) of $\mathrm{Na}^{+}$. Through fitting the cathodic peak current and scan rate (Figure $6 \mathrm{f}$ ), it can be found that GDOT electrode displays much higher apparent diffusion coefficient of $\mathrm{Na}^{+}$with a slope of 0.38 compared to that of the pure GO electrode (0.1). The accelerated $\mathrm{Na}^{+}$diffusion behavior of the GDOT electrode can be ascribed to the ultrathin $\mathrm{Na}^{+}$transport pathway as well as electron highway originating from the well-designed conductive PEDOT fibers.

\section{Conclusions}

In summary, functional surface engineering of GO nanosheets towards enhanced sodium storage was realized by in situ polymerization of EDOT monomers under ambient conditions. Uniform PEDOT fibers can be deposited on GO within a short reaction time (40 min). As compared with the bare GO, 
GDOT exhibits high reversible capacity ( $338 \mathrm{mAh} \mathrm{g}^{-1}$ ), good cycling stability ( $234 \mathrm{mAh} \mathrm{g}^{-1}$ after 400 cycles) and rate capabilities (e.g., $62 \mathrm{mAh} \mathrm{g}^{-1}$ at $30 \mathrm{~A} \mathrm{~g}^{-1}$ ). The present results sheds light on developing high-efficiency carbon electrode materials for rechargeable batteries and also holds great potential for other energy storage devices.

Supplementary Materials: The following are available online at http:/ /www.mdpi.com/1996-1944/11/10/2032/s1, Figure S1: Cycling performance of the pure SWCNT electrode for SIBs at a current density of $100 \mathrm{~mA} \mathrm{~g}^{-1}$.

Author Contributions: Z.P. and P.Z. designed and conducted the experiments, performed the data analysis, and wrote the manuscript. Y.Z. edited and revised manuscript. All authors approved the final version of the manuscript.

Funding: The authors wish to thank for the Sichuan University of Science and Engineering Talent Introduction Project (No.2016RCL35), Opening Project of Key Laboratories of Fine Chemicals and Surfactants in Sichuan Provincial Universities (2018JXY04) and Major Project of Education Department in Sichuan (18ZA0346).

Conflicts of Interest: The authors declare no conflict of interest.

\section{References}

1. Kang, H.; Liu, Y.C.; Cao, K.Z.; Zhao, Y.; Jiao, L.F.; Wang, Y.J.; Yuan, H.T. Update on anode materials for Na-ion batteries. J. Mater. Chem. A 2015, 3, 17899-17913. [CrossRef]

2. Mauger, A.; Xie, H.M.; Julien, C.M. Composite anodes for lithium-ion batteries: status and trends. AIMS Mater. Sci. 2016, 3, 1054-1106. [CrossRef]

3. Wei, L.; Shen, F.; Bommier, C.; Zhu, H.L.; Ji, X.L.; Hu, L.B. Na-Ion Battery Anodes: Materials and Electrochemistry. Acc. Chem. Res. 2016, 49, 231-240.

4. Liang, Y.; Lai, W.H.; Miao, W.Z.; Chou, S.L. Nanocomposite Materials for the Sodium-Ion Battery: A Review. Small 2018, 14, 1702514. [CrossRef] [PubMed]

5. You, Y.; Manthiram, A. Progress in High-Voltage Cathode Materials for Rechargeable Sodium-Ion Batteries. Adv. Energy. Mater. 2018, 8, 1701785. [CrossRef]

6. Zhang, Y.; Sun, W.; Luo, Z.Z.; Zheng, Y.; Yu, Z.; Zhang, D.; Yang, J.; Tan, H.T.; Zhu, J.; Wang, X. Functionalized Few-layer Black Phosphorus with Super-Wettability towards Enhanced Reaction Kinetics for Rechargeable Batteries. Nano Energy 2017, 40, 576-586. [CrossRef]

7. Jache, B.; Adelhelm, P. Use of Graphite as a Highly Reversible Electrode with Superior Cycle Life for Sodium-Ion Batteries by Making Use of Co-Intercalation Phenomena. Angew. Chem. Int. Ed. 2014, 53, 10169-10173. [CrossRef] [PubMed]

8. Wu, Z.S.; Ren, W.; Xu, L.; Li, F.; Cheng, H.M. Doped Graphene Sheets As Anode Materials with Superhigh Rate and Large Capacity for Lithium Ion Batteries. ACS Nano 2011, 5, 5463-5471. [CrossRef] [PubMed]

9. Walter, M.; Doswald, S.; Krumeich, F.; He, M.; Widmer, R.; Stadie, N.P.; Kovalenko, M.V. Oxidized Co-Sn nanoparticles as long-lasting anode materials for lithium-ion batteries. Nanoscale 2018, 10, 3777-3783. [CrossRef] [PubMed]

10. Zhang, X.H.; Lai, F.Y.; Chen, Z.M.; He, X.C.; Li, Q.Y.; Wang, H.Q. Metallic Sb nanoparticles embedded in carbon nanosheets as anode material for lithium ion batteries with superior rate capability and long cycling stability. Electrochim. Acta 2018, 283, 1689-1694. [CrossRef]

11. Fu, Y.Q.; Wei, Q.L.; Zhang, G.X.; Sun, S.H. Batteries: Advanced Phosphorus-Based Materials for Lithium/Sodium-Ion Batteries: Recent Developments and Future Perspectives. Adv. Energy. Mater. 2018, 8, 1870057. [CrossRef]

12. Li, F.; Zou, Q.Q.; Xia, Y.Y. CoO-loaded graphitable carbon hollow spheres as anode materials for lithium-ion battery. J. Power Sources 2008, 177, 546-552. [CrossRef]

13. Liu, Z.; Lu, T.C.; Song, T.; Yu, X.Y.; Lou, X.W.D.; Paik, U. Structure-designed synthesis of FeS $\mathrm{F}_{2} @ \mathrm{C}$ yolk-shell nanoboxes as a high-performance anode for sodium-ion batteries. Energy Environ. Sci. 2017, 10, 1576-1580. [CrossRef]

14. Zhu, Y.J.; Wen, Y.; Fan, X.L.; Gao, T.; Han, F.D.; Luo, C.; Liou, S.C.; Wang, C.S. Red phosphorus-single-walled carbon nanotube composite as a superior anode for sodium ion batteries. ACS Nano 2015, 9, 3254-3264. [CrossRef] [PubMed] 
15. Gaddam, R.R.; Jiang, E.; Amiralian, N.; Annamalai, P.K.; Martin, D.J.; Kumar, N.A.; Zhao, X.S. Spinifex nanocellulose derived hard carbon anodes for high-performance sodium-ion batteries. Sustain. Energy Fuels 2017, 1, 1090-1097. [CrossRef]

16. Pan, L.; Zhao, H.B.; Shen, W.C.; Dong, X.W.; Xu, J.Q. Surfactant-assisted synthesis of a $\mathrm{Co}_{3} \mathrm{O}_{4} /$ reduced graphene oxide composite as a superior anode material for Li-ion batteries. J. Mater. Chem. A 2013, 1, 7159-7166. [CrossRef]

17. Gao, M.R.; Liang, J.X.; Zheng, Y.R.; Xu, Y.F.; Jiang, J.; Gao, Q.; Li, J.; Yu, S.H. An Efficient Molybdenum Disulfide/Cobalt Diselenide Hybrid Catalyst for Electrochemical Hydrogen Generation. Nat. Chem. 2015, 6, 5982-5988. [CrossRef] [PubMed]

18. Ponrouch, A.; Goñi, A.; Palacín, M.R. High Capacity Hard Carbon Anodes for Sodium Ion Batteries in Additive Free Electrolyte. Electroche. Commun. 2013, 27, 85-88. [CrossRef]

19. Nithya, C.; Gopukumar, S. RGO/Nano Sb Composite: A High Performance Anode Material for $\mathrm{Na}^{+}$Ion Batteries and Evidence for the Formation of Nanoribbons from the Nano rGO Sheet during Galvanostatic Cycling. J. Mater. Chem. A 2014, 2, 10516-10525. [CrossRef]

20. Huang, T.; Lu, D.; Ma, L.; Xi, X.; Liu, R.L.; Wu, D.Q. A hit-and-run strategy towards perylene diimide/reduced graphene oxide as high performance sodium ion battery cathode. Chem. Eng. J. 2018, 349, 66-71. [CrossRef]

21. Hummers, W.S., Jr.; Offeman, R.E. Preparation of Graphitic Oxide. J. Am. Chem. Soc. 1958, 80, 1339. [CrossRef]

22. Lee, J.T.; Chu, Y.J.; Wang, F.M.; Yang, C.R.; Li, C.C. Aqueous Processing of Lithium-Ion Battery Cathodes Using Hydrogen Peroxide-Treated Vapor-Grown Carbon Fibers for Improvement of Electrochemical Properties. J. Mater. Sci. 2007, 42, 10118-10123. [CrossRef]

23. Du, W.C.; Wu, M.M.; Zhang, M.; Xu, G.C.; Gao, T.T.; Qian, L.; Yu, X.W.; Chi, F.Y.; Li, C.; Shi, G.Q. High-quality graphene films and nitrogen-doped organogels prepared from the organic dispersions of graphene oxide. Carbon 2018, 129, 15-20. [CrossRef]

24. Yang, D.; Velamakanni, A.; Bozoklu, G.; Park, S.; Stoller, M.; Piner, R.D.; Stankovich, S.; Jung, I.; Field, D.A.; Ventrice, C.A. Chemical Analysis of Graphene Oxide Films after Heat and Chemical Treatments by X-Ray Photoelectron and Micro-Raman Spectroscopy. Carbon 2009, 47, 145-152. [CrossRef]

25. Dreyer, D.R.; Park, S.; Bielawski, C.W.; Ruoff, R.S. The Chemistry of Graphene Oxide. Chem. Soc. Rev. 2010, 39, 228-240. [CrossRef] [PubMed]

26. Zhang, H.; Hasa, I.; Passerini, S. Beyond Insertion for Na-Ion batteries: Nanostructured alloying and conversion anode materials. Adv. Energy Mater. 2018, 8, 1702582. [CrossRef] 